\title{
Breast cancer in women with primary biliary cirrhosis
}

\author{
B M GOUDIE, A D BURT, P BOYLE, G MACFARLANE, G G BIRNIE, P R MILLS, \\ C R GILLIS, R N M MACSWEEN, G WATKINSON
}

\begin{abstract}
The occurrence of extrahepatic malignancy was studied in 195 unselected patients who satisfied predetermined biochemical, immunological, and histological criteria for the diagnosis of primary biliary cirrhosis. The incidence of breast cancer in women with primary biliary cirrhosis was found to be significantly higher than in an age and sex matched control population from the same well defined geographical area $(\mathbf{p}<0.0015)$.

The association of breast cancer and primary biliary cirrhosis remains unexplained, though diminished immunological surveillance, fat soluble vitamin deficiency, or endocrine dysfunction may play a part.
\end{abstract}

\section{Introduction}

Primary biliary cirrhosis is an uncommon form of chronic cholestatic liver disease. It is associated with disturbance of both humoral and cellular immunity and is characterised by the presence of antimitochondrial antibody, which may be detected in the serum of over $95 \%$ of patients. It has been suggested that primary biliary cirrhosis may be associated with an increased incidence of extrahepatic malignancy, but evidence for this is based on the investigation of patients attending specialist referral centres. ${ }^{12}$

We have studied the occurrence of extrahepatic malignancy in all those patients from the west of Scotland who between 1965 and 1980

\footnotetext{
University Departments of Medicine and Pathology, Western Infirmary, Glasgow G11 6NT

B M GOUDIE, MRCP, lecturer in medicine

A D BURT, BSC, MB, registrar in pathology

G MACFARLANE, student

G G BIRNIE, MRCP, senior registrar in gastroenterology

P R MILLS, MD, senior registrar in gastroenterology

R N M MACSWEEN, MD, professor of pathology

G WATKINSON, MD, consultant physician

West of Scotland Cancer Surveillance Unit, Ruchill Hospital, Glasgow

P BOYLE, BSC, senior statistician

C R GILLIS, MD, consultant epidemiologist and director

Correspondence and requests for reprints to: Professor MacSween, university department of pathology.
}

were found to be seropositive for antimitochondrial antibody and who satisfied predetermined histological, immunological, and biochemical criteria for the diagnosis of primary biliary cirrhosis.

\section{Patients and methods}

The study population was ascertained by $(a)$ identification of all patients from the west of Scotland who were found to be seropositive for antimitochondrial antibody between 1965 and $1980,(b)$ examination of all available case records, and $(c)$ review of all available liver biopsy specimens. During the study period serum samples from all suspected cases of primary biliary cirrhosis were tested for antimitochondrial antibody in the regional immunopathology laboratory; positive results were recorded in 715 patients. Case records for 647 of these $(90 \%)$ were available for inspection, and 532 liver biopsy specimens from 373 patients were obtained for review.

Primary biliary cirrhosis was diagnosed in patients who either $(a)$ were positive for antimitochondrial antibody and showed histological evidence of characteristic granulomatous or lymphocytic injury to small and medium bile duct radicles, or $(b)$ had an antimitochondrial antibody titre greater than 50 and serum alkaline phosphatase activity greater than twice normal plus one or a combination of the following histological appearances: paucity of interlobular bile ducts; biliary type piecemeal necrosis; and biliary type cirrhosis.

The number of extrahepatic malignancies in the study population was ascertained from the records of the West of Scotland Cancer Registry. The diagnosis of each tumour was confirmed by re-examination of biopsy or necropsy tissue, or both. Cases for which histological material could not be obtained were excluded. Non-melanoma skin tumours were excluded from analysis because of the uncertainty about their incidence in the general population.

The expected number of tumours was calculated using average annual age specific cancer incidence rates for the west of Scotland ${ }^{3}$ and the age specific person years of risk of the study population. ${ }^{4}$ The probability of obtaining an observed rate was tested assuming a Poisson distribution.

\section{Results}

One hundred and ninety five patients (171 women, 24 men) satisfied our criteria for the diagnosis of primary biliary cirrhosis. Their mean age at presentation was 54 years (range 25-78) and the mean duration of follow up six years (range $0-17$ )

In 13 cases ( 10 women, 3 men) a diagnosis of histologically confirmed extrahepatic malignancy was recorded after presentation with primary biliary cirrhosis. The table lists the sites of the tumours and summarises the 
Details of patients with primary biliary cirrhosis who later presented with extrahepatic malignancy

\begin{tabular}{|c|c|c|c|c|c|}
\hline \multirow[b]{2}{*}{$\begin{array}{c}\text { Case } \\
\text { No }\end{array}$} & \multirow[b]{2}{*}{ Sex } & \multicolumn{2}{|r|}{ Tumour } & \multicolumn{2}{|c|}{ Age at presentation (years) } \\
\hline & & Site & Type & $\begin{array}{l}\text { Primary biliary } \\
\text { cirrhosis }\end{array}$ & Malignancy \\
\hline 1 & & Breast & Carcinoma & 51 & 55 \\
\hline 2 & $\mathrm{~F}$ & Breast & Carcinoma & 43 & 51 \\
\hline 3 & $\mathrm{~F}$ & Breast & Carcinoma & 58 & 66 \\
\hline 4 & $\mathrm{~F}$ & Breast & Carcinoma & 67 & 76 \\
\hline 5 & $\mathrm{~F}$ & Breast & Carcinoma & 61 & 65 \\
\hline 6 & $\mathrm{~F}$ & Breast & Carcinoma & 47 & 51 \\
\hline 7 & $\mathrm{~F}$ & Bronchus & Large cell anaplastic carcinoma & 63 & 65 \\
\hline 8 & $\mathrm{~F}$ & Bladder & Transitional cell carcinoma & 62 & 71 \\
\hline 9 & $\mathrm{~F}$ & Cervix & Squamous carcinoma & 57 & 58 \\
\hline 10 & $\mathrm{~F}$ & Stomach & Adenocarcinoma & 57 & 60 \\
\hline 11 & $\mathbf{M}$ & Bronchus & Squamous carcinoma & 65 & 70 \\
\hline 12 & $M$ & Colon & Carcinoma & 67 & 71 \\
\hline 13 & $\mathbf{M}$ & Hodgkin's disease & & 53 & 54 \\
\hline
\end{tabular}

clinical and histological details. The incidence of carcinoma of the breast was significantly increased in women with primary biliary cirrhosis-that is, six cases observed compared with 1.59 expected $(p<0.0015)$. There was no excess of other extrahepatic tumours in patients of either sex.

\section{Discussion}

Our observation of an increased incidence of breast cancer in women with primary biliary cirrhosis corroborates the findings of
Wolke et al. ${ }^{2}$ Though close surveillance of hospital patients may result in increased detection of malignancy and produce erroneous evidence of an association with other disease, ${ }^{5}$ we think it unlikely that this phenomenon would result in the increased detection of breast tumours only.

The biological basis for an association between primary biliary cirrhosis and breast cancer is obscure, but defective immune surveillance, endocrine dysfunction, or deficiency of fat soluble vitamins may be implicated. We suggest that these factors should be examined in further studies of patients with primary biliary cirrhosis and that the frequency of extrahepatic malignancy should be investigated in patients with other forms of chronic liver disease.

This study was supported by a grant from the biomedical research committee of the Scottish Home and Health Department.

\section{References}

1 Mills PR, Boyle P, Quigley EMM, et al. Primary biliary cirrhosis: an increased incidence of extrahepatic malignancies? $\mathcal{f}$ Clin Pathol 1982;35:541-3.

2 Wolke AM, Schaffner F, Kapelman B, Sacks HS. Malignancy in primary biliary cirrhosis. Hig incidence of breast cancer in affected women. Am $\mathcal{J}$ Med 1984;76:1075-8.

3 Gillis CR, Boyle P, Hole DJ, Graham A. Scotland West Registry. In: Waterhouse JAH, Muir CS, Shammugaratnam K, Powell J, eds. Cancer incidence in five continents. Vol 4. Lyon: IARC Scientific Publications, 1982:592-5.

4 Hill ID. Computing man years of risk. British Journal of Preventive and Social Medicine 1972;26:132-4.

5 Berkson J. The statistical study of association between smoking and lung cancer. Proceedings of the Staff Meetings of the Mayo Clinic 1955;30:319-48.

(Accepted 5 September 1985)

\title{
Loss of pulsatile luteinising hormone secretion in men with chronic renal failure
}

\author{
R S C RODGER, L MORRISON, J H DEWAR, R WILKINSON, M K WARD, \\ D N S KERR
}

\begin{abstract}
In an attempt to determine the nature of hypothalamic and pituitary dysfunction in renal failure the secretory patterns of luteinising hormone were measured in men with end stage renal disease and compared with those in healthy controls and renal transplant recipients of similar age distribution. Mean luteinising hormone and oestradiol concentrations were significantly higher and the number of luteinising hormone secretory pulses was significantly lower in uraemic men compared with controls.
\end{abstract}

\footnotetext{
Departments of Medicine, Freeman Hospital and Royal Victoria Infirmary, Newcastle upon Tyne

R S C RODGER, MB, MRCP, lecturer

R WILKINSON, MD, FRCP, reader

M K WARD, FRCP, senior lecturer

Supraregional Assay Service, Royal Victoria Infirmary, Newcastle upon Tyne L MORRISON, AIMLF, medical laboratory scientific officer

J H DEWAR, PHD, principal hospital biochemist

Royal Postgraduate Medical School, London W12

D N S KERR, MSC, FRCP, dean

Correspondence to: Dr Rodger, Department of Medicine, Royal Victoria Infirmary, Newcastle upon Tyne NE1 4LP.
}

Plasma testosterone and oestradiol concentrations were significantly lower in renal transplant recipients than normal men, but there were no significant differences in mean gonadotropin concentrations or the number of pulses of luteinising hormone between the two groups. As pulses of luteinising hormone are thought to reflect episodic gonadotropin releasing hormone from the hypothalamus these data suggest that uraemia interferes with central mechanisms controlling synchronised release of gonadotropin releasing hormone. This defect appears to be reversible after successful transplantation.

\section{Introduction}

Testicular dysfunction as manifested by decreased libido, potency, and testicular size is well recognised in men with end stage renal disease. ${ }^{1}$ Plasma testosterone concentrations and rates of testosterone production are often low and there is diminished or absent spermatogenesis. ${ }^{2}$ These changes may be reversed and fertility restored after successful renal transplantation. ${ }^{3}$

The importance of pulsatile gonadotropin releasing hormone in the physiology of the male reproductive system has been shown by its therapeutic effect in the management of hypogonadotropic hypogonadism. ${ }^{+}$Secretion of pulsatile luteinising hormone itself is thought to be important to allow gonadotropin receptors in the testes to be maintained as sustained high concentrations lead to loss of receptors. ${ }^{56}$ In this study the secretory patterns of luteinising 